\title{
PENGGUNAAN METODE DISKUSI KELOMPOK DAN PEMBERIAN TUGAS DALAM UPAYA MENINGKATKAN PRESTASI BELAJAR EKONOMI MATERI PERTUMBUHAN EKONOMI SISWA KELAS XI IPS 4 SMA NEGERI 1 PUNGGUR SEMESTER GANJIL TAHUN PELAJARAN 2015/2016.
}

\author{
Purwati \\ SMA N 1 Punggur \\ Purwantispd72@gmail.com
}

\begin{abstract}
To get good result in learning process, teacher should be able to improve herself by using many kinds of methods so that the result can be improved and students can be active in teaching learning process. The purpose of this research is to know whether the use of discussion and giving task can improve learning achievement in a material of economic growth at the class of XI IPS 4 SMAN 1 Punggur year 2015/2016. To get good result in learning process teacher should be able to improve herself by using many kinds of methods so the result can be improved and students can be active in teaching learning process. The purpose of this research is to know whether the use of discussion and giving task can improve learning achievement in a material of economic growth at the class of XI IPS 4 SMAN 1 Punggur year 2015/2016. The location of this research is in SMAN 1 Punggur. It is done for 3 months , August to October 2015. Subject of this research is Class XI IPS 4 of SMAN 1 Punggur in the academic year of 2015/ 2016. Technique of collecting data used are : observation, documentation and data analysis interview by using qualitative descriptive analysis. Research procedure uses classroom action research method that consists of 2 cycles. The result of the classroom action research shows that In pre cycle, students who pass / succeed are 10 from 31 students or $32.14 \%$ and fail students are 21 from 31 students or equal to $6.86 \%$. After getting treatment in the first cycle, passed students increases to 22 from 31 students or $75 \%$ while fail students decrease 10 from 31 students or $25 \%$. In the second cycle, passed students increases to 29 from 31 students or $92.86 \%$ while failed students only 2 from 31 students. Based on the data above it can be concluded that by using discussion method and giving task can improve thestudents' economy achievement with economic growth material at the XIGrade of Social Science 4 in SMAN 1 Punggur on odd semester in the academic year of 2015/2016is true.
\end{abstract}

Keywords : Discussion method and giving task, Learning achievement.

\section{PENDAHULUAN}

Pendidikan merupakan suatu upaya untuk meningkatkan sumber daya manusia, dengan menciptakan manusia cerdas dan maju serta diimbangi dengan mutu pendidikan yang lebih baik. Proses pendidikan yang optimal apabila guru mampu merencanakan pelaksanaan pendidikan sampai evaluasi (Subrata 1997:19). Dengan demikian proses belajar merupakan salah satu kegiatan pokok dalam proses pembelajaran, berhasil tidaknya pencapaian pendidikan banyak tergantung pada bagimana proses belajar 
yang dialami oleh siswa sebagai anak didik dan guru dalam melakukan proses pembelajaran.

Demikian halnya dengan pembelajaran ekonomi yang dilakukan di kelas XI IPS 4 semester ganjil di SMA Negeri 1 Punggur Lampung tengah pada tahun 2015/2016 daya serap yang ada pada diri siswa sangat rendah terlihat dari 31 siswa kelas XI IPS 4 ada 16 anak yang hasil belajarnya di bawah KKM, hal ini disebabkan masih mengandalkan teori dan kurang menyadari pentingnya pendekatan pembelajaran. Sehingga disini guru berupaya untuk menerapkan metode diskusi dalam pemahaman dan pemberian tugas untuk meningkatkan prestasi belajar ekonomi kelas XI IPS 4 di SMA Negeri Punggur.

\section{KAJIAN PUSTAKA}

\section{Pengertian Belajar}

Belajar adalah aktivitas yang menghasilkan perubahan pada diri yang belajar baik aktual maupun potensial, perubahan itu pada dasarnya karena usaha yang berasal dari diri individu baik ingatan, pengetahuan baik yang bisa diamati maupun tidak dapat diamati secara langsung dikarenakan karena pengalaman (Nasution 1992:3). Dengan ciri-ciri sebagai berikut: a. Belajar membawa perubahan pada diri individu yang sedang belajar. b. Perubahan diperoleh dari kemampuan baru yang terjadi dalam waktu yang relatif lama dan berbekas, c. Perubahan itu terjadi karena pengalaman atau latihan, d. Belajar merupakan interaksi aktif antara individu dengan lingkungan dan e. Belajar suatu stimulus bersama dengan isi ingatan dan pengetahuan.

Hakekat belajar menurut Abu Ahmadi dan Supriyono (2004:128-130) ada enam ciri perubahan tingkah laku dalam belajar yaitu: 1) perubahan yang terjadi secara sadar. 2) perubahan dalam belajar bersifat fungsional. 3)Perubahan dalam belajar bersifat positif dan aktif. 4)perubahan yang terjadi bukan bersifat sementara. 5) perubahan dalam belajar bertujuan atau terarah. 6) perubahan mencakup seluruh aspek tingkah laku. Dengan demikian sebuah perubahan diharapkan mendapatkan sebuah pembelajaran hidup yang nantinya dapat dimanfaatkan dalam kehidupan masyarakat yang berawal dari sistem pembelajaran yang sederhana namun membawa perubahan yang berarti dalam kehidupan.

Interaksi pembelajaran adalah suatu kegiatan yang bersifat interaktif dari berbagai komponen untuk mewujudkan tercapainya tujuan pembelajaran yang telah ditetapkan. Interaksi yang diupayakan guru baik di dalam maupun di 
luar kelas memposisikan hubungan antara guru dan siswa atau sebaliknya. Guru, siswa dan materi merupakan tiga unsur utama yang terlibat langsung dalam proses belajar sehingga dipandang perlu untuk mengaktifkan siswa dalam pembelajaran ekonomi, dimana siswa dianggap kurang mempunyai minat terhadap ekonomi.

\section{Metode Diskusi}

Metode diskusi adalah cara penyajian bahan pelajaran dimana guru memberi kesempatan kepada para siswa (kelompok siswa) untuk mengadakan perbincangan ilmiah guna mengumpulkan pendapat, membuat kesimpulan, atau menyusun berbagai alternatif pemecahan atas suatu masalah.( Kusmana, 2003:171). Dengan fungsi diskusi adalah 1) melatih berpendapat mempertahankannya, 2)melatih menghargai pendapat orang lain, 3) melatih menggunakan pengetahuan guna memecahkan masalah. Dengan kelebihannya a) melibatkan siswa secara langsung dalam proses belajar mengajar, b) memupuk kepercayaan pada diri sendiri, c) menggabungkan berbagai pendapat dari berbagai sumber, d) menghasilkan pandangan baru, e) memudahkan pencapaian tujuan, f) melatih siswa belajar bertukar pikiran dan berpikir secara terarah, g) memupuk sikap toleran, mau menerima dan memberi, $\mathrm{h}$ ) mengembangkan kebebasan intelek siswa, i) memberikan kesempatan kepada siswa untuk menguji, mengubah dan memperbaiki pandangannya, serta j) memberi kesempatan kepada mereka untuk menjalin hubungan atau kerja sama berikutnya. Sedangkan kelemahannya adalah a) hasil diskusi tidak bisa dicapai dengan baik, sebab diskusi menyimpang dari pokok bahasan, b) diskusi tidak dapat berfungsi sebagaimana mestinya jika peserta tidak mempunyai latar belakang pengetahuan tentang masalah yang didiskusikan, c) diskusi tidak menjamin prestasi, d) diskusi tidak akan melibatkan segenap peserta bila pemimpin kurang bijaksana e) diskusi mungkin dikuasai atau diambil alih oleh orang-orang tertentu saja. Untuk mengatasinya Kusmayana (2003:173) menjelaskan untuk mengatasi kelemahan diskusi hendaknya 1) topik diskusi yang dapat menarik perhatian siswa, 2) mengusahakan keterlibatan anak didik, 3) menghindari dominasi siswa, 4)tempat strategis/mendukung.5) memberi penghargaan setiap anak didik yang berpendapat.

\section{Metode Pemberian Tugas}

Metode pemberian tugas diartikan sebagai suatu format interaksi belajar mengajar yang ditandai adanya satu atau lebih tugas yang diberikan oleh guru, 
dimana penyelesaian tugas tersebut dilakukan secara perseorangan atau secara kelompok sesuai dengan perintahnya. Sujana (2007:201). Kelebihan dari pemberian tugas adalah a) hasil belajar sendiri akan dapat diingat lebih lama, b) mempunyai kesempatan dalam berinisiatif. Sedangkan kelemahannya adalah a) adanya penipuan karena meniru hasil orang lain, b) tugas dapat dikerjakan orang lain, c)adanya perbedaan tingkat kemampuan berinisiatif. Untuk mengatasi kelemahan tersebut adalah 1) adanya pertalian antara tugas dan masalah yang pernah dihadapi 2) tugas memberi manfaat anak didik, 3) waktu tidak terlalu lama, 4) anak didik mengetahui alat dan cara menilai hasil tugas.

\section{METODE PENELITIAN}

Rincian kegiatan Penelitiannya meliputi 1) Persiapan penelitian, 2)
Koordinasi persiapan tindakan, 3)

Pelaksanaan terdiri dari perencanaan tindakan, pelaksanaan tindakan, Monitoring dan evaluasi dan kemudian refleksi 4) Penyusunan laporan.

Setting kelas yang digunakan adalah kelas XI IPS 4 sebagai objek penelitian dan subjeknya adalah guru peneliti dibantu oleh guru ekonomi lain sebagai observer, dengan data yang didapatkan berasal dari informasi, observasi dan dokumen atau arsip serta wawancara yang dilakukan kepada pihak-pihak yang terkait dengan penelitian seperti siswa dan guru ekonomi sebagai teman sejawat.

\section{PEMBAHASAN HASIL PENELITIAN}

Penguasaan materi pada kegiatan pra siklus adalah nilai rata-rata 53,7 dengan nilai tertinggi 75 dan nilai terendah 30 hal ini terlihat dalam grafik dibawah ini:

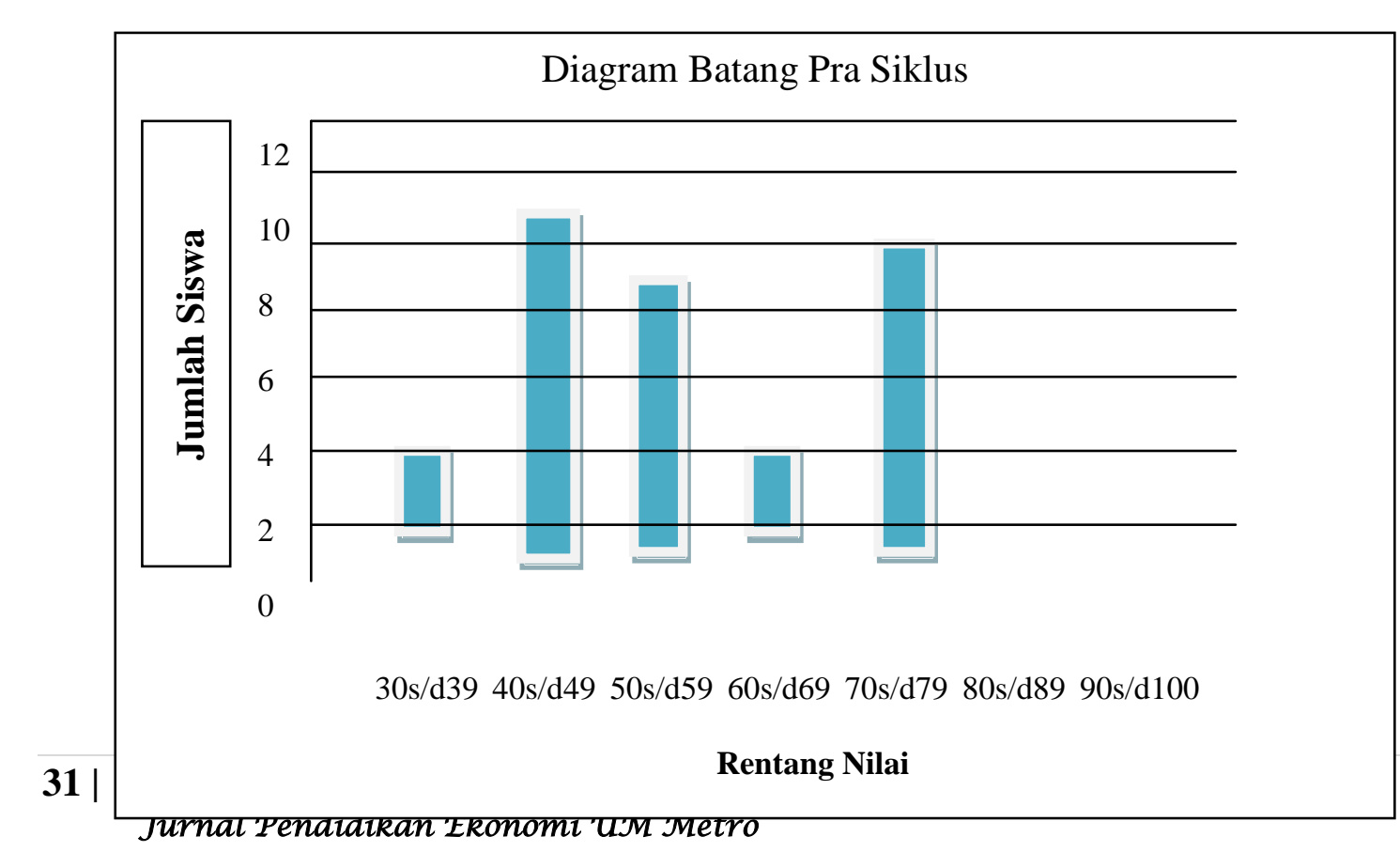




\section{Siklus I}

siklus I adalah, nilai rata-rata 65,3, dengan nilai tertinggi 80 dan nilai tertendah 45 hal

Pada siklus I penguasaan materi sesudah tindakan perbaikan pembelajaran pada

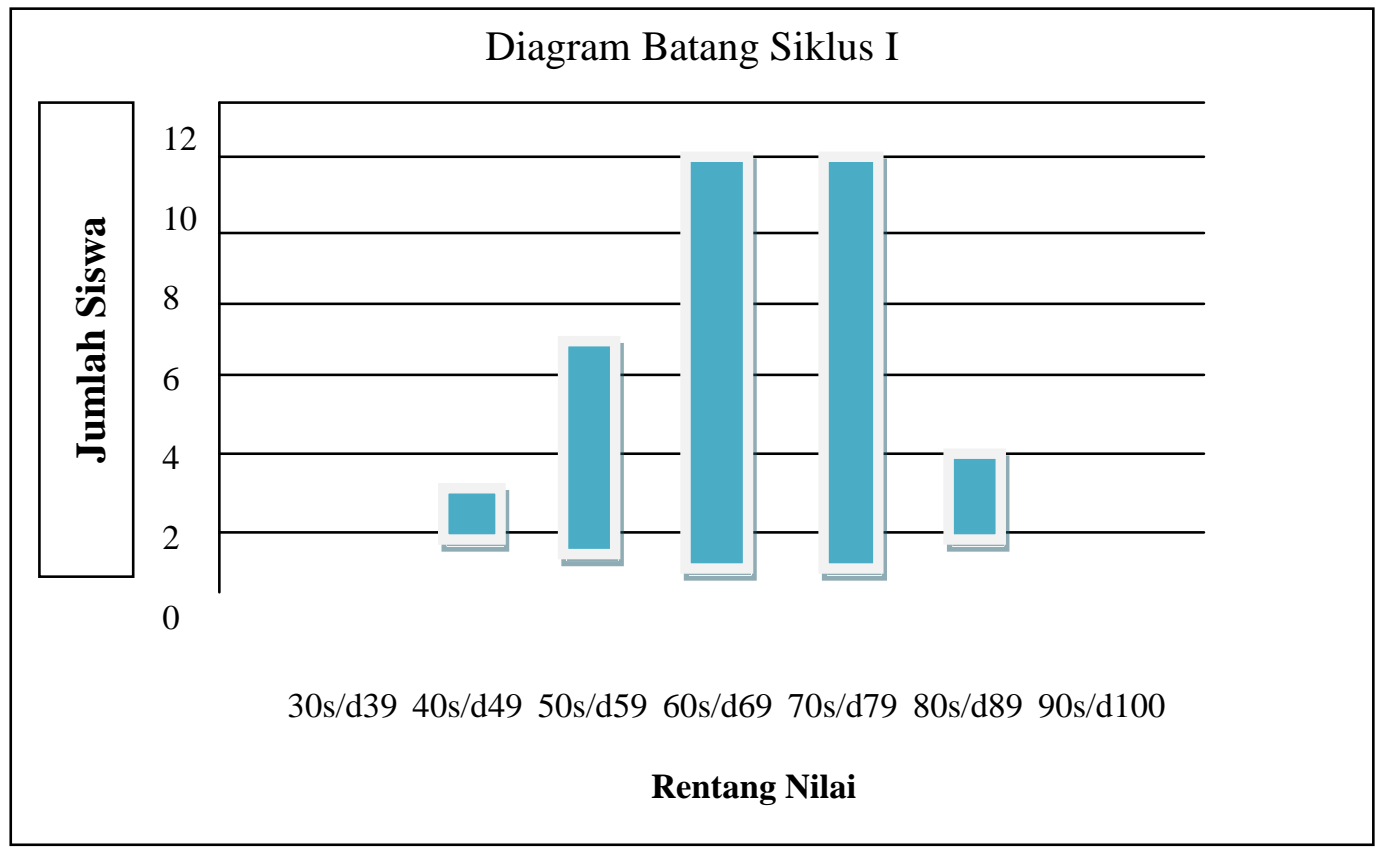

\section{Siklus II}

Penguasaan materi setelah perbaikan pembelajaran pada siklus II adalah, nilai rata-rata 73,7 dengan nilai tertinggi 90 , dan ini dapat dilihat pada diagram dibawah ini: 
Sehingga rekapitulasi pengelompokan ketuntasan siswa dalam pembelajaran ekonomi dan presentasenya adalah sebagai berikut:

\section{Rekapitulasi Ketuntasan Siswa dalam Pembelajaran ekonomi} Siswa Kelas XI IPS 4 SMA Negeri 1 Punggur

\begin{tabular}{|l|c|c|c|c|c|c|}
\hline \multirow{2}{*}{ Kriteria } & \multicolumn{2}{|c|}{ Pra Siklus } & \multicolumn{2}{c|}{ Siklus I } & \multicolumn{2}{c|}{ Siklus II } \\
\cline { 2 - 7 } & $\mathrm{N}$ & Persen & $\mathrm{N}$ & Persen & $\mathrm{N}$ & Persen \\
\hline \hline $\begin{array}{l}\text { Tuntas } \\
\text { Nilai } \geq 65\end{array}$ & 9 & $32,14 \%$ & 21 & $75 \%$ & 29 & $92,86 \%$ \\
\hline $\begin{array}{l}\text { Tidak Tuntas } \\
\text { Nilai < 65 }\end{array}$ & 22 & $67,86 \%$ & 10 & $25 \%$ & 2 & $7,14 \%$ \\
\hline \hline Jumlah & 31 & $100 \%$ & 31 & $100 \%$ & 31 & $100 \%$ \\
\hline
\end{tabular}

Dari tabel rekapitulasi ketuntasan siswa dalam pembelajaran ekonomi diatas dapat disajikan diagram batang untuk membandingkan tingkat ketuntasan siswa sebelum perbaikan, siklus I dan siklus II dalam pembelajaran ekonomi di SMA Negeri 1 Punggur kelas XI IPS 4 adalah sebagai berikut: 


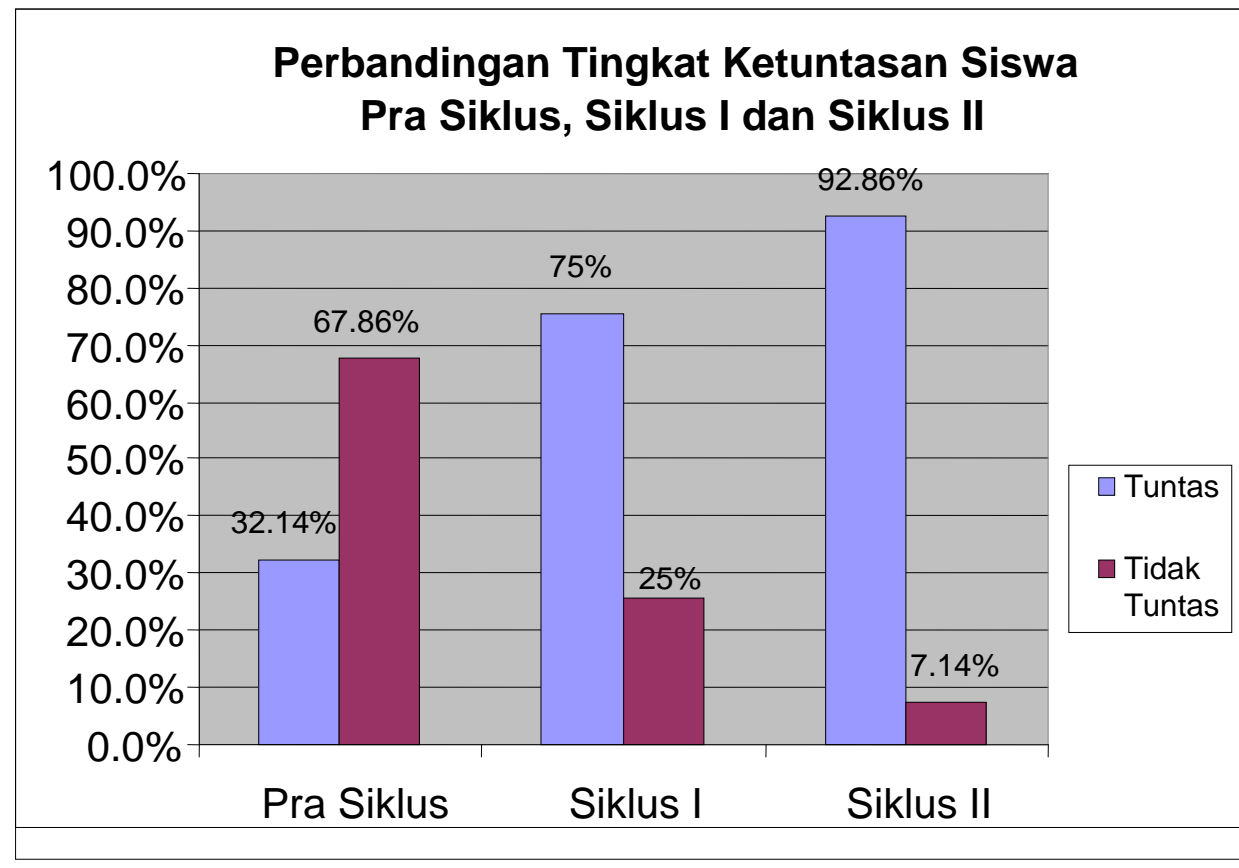

Dari perbandingan tingkat ketuntasan siswa pada tahap pra siklus, siklus I dan siklus II maka didapatkan siswa tidak tuntas sebanyak 67,86\% (21 siswa) dan yang mencapai KKM 10 orang $(32,14 \%)$, kemudian pada siklus I meningkat $75 \%$ siswa tuntas dan $25 \%$ siswa yang belum tuntas namun peningkatan itu juga belum sesuai dengan harpan yaitu $85 \%$, untuk itu dilakukan perbaikan pada siklus II dengan hasil yang dicapai $92,86 \%$ siswa tuntas (29 anak) dan sisanya $7,14 \%$ siswa yang belum tuntas. Namun kemajuan itu sudah sesuai yang diharapkan yaitu diatas $85 \%$ yakni 92,86\% yang menandakan bahwa perbaikan pembelajaran pada siklus II telah berhasil.

\section{Refleksi}

Perbaikan pembelajaran ekonomi dengan metode diskusi dan penugasan terjadi keantusiasan siswa dalam mengikuti pelajaran hal ini terbukti dengan adanya peningkatan dari pra siklus 32,14 $\%$ meningkat $75 \%$ pada siklus I, dan meningkat lagi pada siklus II yakni 92,86\%. Keberhasilan ini dikarenakan beberapa hal yaitu:

a. Penyampaian materi pembelajaran dengan menggunakan metode diskusi yang tepat yaitu diskusi kelompok meningkatkan kreativitas dan keaktifan siswa sedangkan pemberian tugas meningkatkan pemahaman siswa.

b. Pada saat pembelajaran berlangsung keadaan kelas menjadi aktif, kreatif dan menyenangkan.

c. Siswa tidak takut untuk mengeluarkan pendapat

d. Siswa tidak bosan lagi dan takut terhadap mata pelajaran ekonomi 
e. Peningkatan frekuensi latihan soal

f. Memberikan pengakuan kepada siswa berprestasi

g. Siswa mendapat kesempatan mengajukan pertanyaan dan merespon pertanyaan guru

h. Memberikan latihan dan tugas.

Sedangkan keberhasilan proses pembelajaran yang dilakukan dari tahapan siklus I dan II dikarenakan sebagai berikut:

a. Dalam perbaikan proses pembelajaran guru menggunakan metode yang tepat dengan melibatkan siswa secara optimal

b. Dalam proses pembelajaran siswa berperan aktif sehingga situasi kelas menjadi hidup

c. Siswa diberi kesempatan bertanya mengenai hal-hal yang tidak dimengerti.

d. Guru menambah latihan-latihan soal dan dikerjakan secara kelompok dengan diskusi sehingga soal yang sulit dapat diatasi bersama-sama. Setelah kerja kelompok kemudian guru memberikan tugas secara individu sebagai bahan evaluasi.

\section{KESIMPULAN DAN SARAN}

Berdasarkan hasil pengolahan data dari perbaikan pembelajaran yang telah dilaksanakan dapat ditarik kesimpulan :
1. Dengan menggunakan metode diskusi dan pemberian tugas diharapkan siswa aktif dalam pembelajaran ekonomi antara lain dengan banyak berlatih mengerjakan tugas yang dibebankan kepadanya. Selain itu waktu pembelajaran menjadi banyak sehingga siswa dapat memperoleh referensi selain yang diajarkan guru di sekolah.

2. Hasil dari Penelitian Tindakan Kelas ini adalah: Pada kondisi awal pada proses pembelajaran ekonomi kelas XI IPS 4 dengan materi Pemenuhan Kebutuhan, penguasaan materi ekonomi sebelum diadakan perbaikan pembelajaran (pra siklus) siswa yang tuntas dalam pembelajaran adalah 10 dari 31 siswa atau $32,14 \%$ dan siswa yang tidak tuntas dalam pembelajaran adalah 21 dari 31 siswa atau 67,86\%. Penguasaan materi ekonomi sesudah diadakan perbaikan pembelajaran pada siklus I: Siswa yang tuntas dalam pembelajaran adalah 22 dari 31 siswa atau $75 \%$ dan siswa yang tidak tuntas dalam pembelajaran adalah 10 dari 31 siswa atau $25 \%$. Penguasaan materi ekonomi sesudah diadakan perbaikan pembelajaran pada siklus II Siswa yang tuntas dalam pembelajaran sebanyak 29 dari 31 siswa atau $92,86 \%$. dan siswa yang tidak tuntas 
dalam pembelajaran adalah 2 dari 31 siswa atau $7,14 \%$, sehingga ketuntasan $92,86 \%>75 \%$. Berdasarkan hasil penelitian, maka hipotesis tindakan yang mengatakan "Dengan metode diskusi dan pemberian tugas dapat meningkatkan prestasi belajar ekonomi pada materi Pemenuhan Kebutuhan pada siswa kelas XI IPS 4 SMA Negeri 1 Punggur Semester ganjil Tahun Pelajaran 2015/2016", terbukti kebenarannya.

Berdasarkan hasil Penelitian Tindakan Kelas dapat dibuat saran sebagai berikut:

1. Dalam metode pemberian tugas, agar tujuan metode ini tercapai, guru hendaknya mengarahkan agar semua siswa untuk mengerjakan tugas yang dibebankan kepada siswa. Siswa yang tidak mengerjakan tugas hendaknya benar-benar mendapat sanksi agar tidak mengulangi lagi.

2. Hendaknya tugas yang telah diberikan benar-benar dibahas pada pertemuan berikutnya sehingga siswa akan mengetahui benar tidaknya hasil pekerjaannya.

3. Siswa hendaknya benar-benar memahami tujuan pemberian tugas oleh guru yaitu agar pengetahuannya meningkat dan dapat memperluas variasi materi pelajaran khususnya bidang studi ekonomi.

\section{DAFTAR PUSTAKA}

Nasution, S. 1992. Metode Research. Bandung: Jemmars

Pachrudin, Kusmana. 2003, Proses Belajar Mengajar : Azas, Strategi, Metode, Jurusan Pendidikan Dunia Usaha, FPIPS IKIP Bandung.

Sudjana, Nana. 2007. Penelitian Dan Penilaian Pendidikan. Bandung. Sinar Baru Algensindo

Surabrata. 1997. Psikologi Perkembangan. Bandung. PT. Gramedia

Supriyono, Widodo. 2004. Psikologi Belajar. PT Reneka Cipta. 